\title{
Modelling and Evaluation of the Thermohydraulic Performance of Finned-Tube Supercritical Carbon Dioxide Gas Coolers
}

\author{
Lei Chai ${ }^{1, * \mathbb{D}}$, Konstantinos M. Tsamos ${ }^{2}$ and Savvas A. Tassou ${ }^{1}$ (D) \\ 1 RCUK Centre for Sustainable Energy Use in Food Chains (CSEF), Institute of Energy Futures, Brunel \\ University London, Uxbridge, Middlesex UB8 3PH, UK; savvas.tassou@brunel.ac.uk \\ 2 Hubbard Products Ltd, Ipswich IP3 9RR, UK; k.tsamos@hubbardproducts.com \\ * Correspondence: Lei.Chai@brunel.ac.uk; Tel.: +44-189-526-5834
}

Received: 31 January 2020; Accepted: 21 February 2020; Published: 25 February 2020

\begin{abstract}
This paper investigates the thermohydraulic performance of finned-tube supercritical carbon dioxide $\left(\mathrm{sCO}_{2}\right)$ gas coolers operating with refrigerant pressures near the critical point. A distributed modelling approach combined with the $\varepsilon$-NTU method has been developed for the simulation of the gas cooler. The heat transfer and pressure drop for each evenly divided segment are calculated using empirical correlations for Nusselt number and friction factor. The model was validated against test results and then used to investigate the influence of design and operating parameters on local and overall gas cooler performance. The results show that the refrigerant heat-transfer coefficient increases with decreasing temperature and reaches its maximum close to the pseudocritical temperature before beginning to decrease. The pressure drop increases along the flow direction with decreasing temperature. Overall performance results illustrate that higher refrigerant mass flow rate and decreasing finned-tube diameter lead to improved heat-transfer rates but also increased pressure drops. Design optimization of gas coolers should take into consideration their impact on overall refrigeration performance and life cycle cost. This is important in the drive to reduce the footprint of components, energy consumption, and environmental impacts of refrigeration and heat-pump systems. The present work provides practical guidance to the design of finned-tube gas coolers and can be used as the basis for the modelling of integrated $\mathrm{sCO}_{2}$ refrigeration and heat-pump systems.
\end{abstract}

Keywords: modelling; thermohydraulic performance; finned-tube gas cooler; supercritical carbon dioxide

\section{Introduction}

Due to growing environmental awareness and concerns, carbon dioxide $\left(\mathrm{CO}_{2}\right)$ is becoming an important commercial and industrial fluid, profiting from its environmental credentials and its advantageous characteristics, such as being nontoxic and nonflammable and having low viscosity and a large refrigeration capacity. Since the early 1990s, when Lorentzen published a patent application for a transcritical $\mathrm{CO}_{2}$ automotive air conditioning system [1], researchers have paid much attention to the use of $\mathrm{CO}_{2}$, a potential replacement of the nonenvironmentally friendly refrigerants such as chlorofluorocarbon and hydrochlorofluorocarbons, in refrigeration, air conditioning, and heat-pump systems [2-5]. For these applications, the thermophysical properties of $\mathrm{CO}_{2}$ (critical point $31.1^{\circ} \mathrm{C}$ and 73.7 bar) and its thermohydraulic performance in gas coolers (operating pressure up to 140 bar) require special attentions. A gas cooler with improved performance can reduce both the power consumption to operate the compressor and the difficulty in manufacturing the compressor, leading to a considerable reduction in manufacturing and operation capital costs. 
Among the air-coupled $\mathrm{CO}_{2}$ gas coolers, the finned-tube heat exchanger is generally considered to be potentially applicable to gas-cooling devices [6]. Hwang et al. [7], Zilio et al. [8], Ge et al. [9], Tsamos et al. [10], and Santosa et al. [11] experimentally tested the thermohydraulic performance of finned-tube supercritical carbon dioxide $\left(\mathrm{sCO}_{2}\right)$ gas coolers. The test parameters included air inlet temperature, air velocity, refrigerant mass flow rate, and operating pressure in gas coolers. In general, the heat transfer of a gas cooler increases with the increase of $\mathrm{sCO}_{2}$ inlet pressure, mass flow rate, and air frontal velocity, and decreases with an increase of air inlet temperature. The $\mathrm{SCO}_{2}$ pressure drop increases with an increase of its inlet pressure, mass flow rate, and air inlet temperature, and decreases with an increase of frontal air velocity. These experimental data usually provide a better understanding of the performance of $\mathrm{sCO}_{2}$ gas coolers, but do not provide sufficient information on local thermohydraulic performance from measurements on full-scale gas coolers [11]. Nevertheless, the test results are useful to validate the proposed models as well as to develop new models and methods for optimization of $\mathrm{sCO}_{2}$ gas cooler design and refrigeration and heat pump cycle operation. For the modelling work, the detailed model for thermohydraulic performance of $\mathrm{sCO}_{2}$ has been developed in recent year, which can accurately predict the local parameter distribution profiles such as temperature, pressure, and heat-transfer rate. Ge et al. [9,12], Singh et al. [13], Gupta et al. [14], and Marcinichen et al. [15] proposed detailed mathematical models for finned-tube gas coolers. The distributed approach and the $\varepsilon-N T U$ method were employed for detailed model development, but different empirical correlations of Nusselt number and friction factor were adopted for heat transfer and pressure drop predictions according to variable applications. During their investigation, Ge et al. [12] and Singh et al. [13] mainly focus on the refrigerant temperature profile. Gupta et al. [14] concentrated on the influence of various combinations of operating conditions on the performance of the overall system based on local environmental conditions in India. Marcinichen et al. [15] investigated the effects of internal tube diameter and plain fin or wavy fin on the local heat transfer and pressure drop properties. It should be pointed out that these modelling studies primarily investigated the performance of finned-tube gas coolers for the refrigerant pressure above the critical point ( $\geq 90 \mathrm{bar}$ ). Recently, Ge et al. [9] extended their detailed model to the operating pressure region near the refrigerant critical point ( $75-90$ bar) and compared it with four specific test conditions of two gas coolers and showed good agreement.

From the previous studies, it can also be identified that the local thermohydraulic performance studies usually focus on the refrigerant temperature profile. However, for the finned-tube $\mathrm{sCO}_{2}$ gas cooler, the air side thermal resistance is much greater than the $\mathrm{CO}_{2}$ side, therefore the temperature distribution can exert significant influence on the local heat-transfer process. For the overall thermohydraulic performance, the researchers mainly emphasize the heat rejection and comparatively few of them investigate the refrigerant outlet temperature and pressure and the pressure drop of the air. However, the refrigerant outlet temperature and pressure influence the compressor performance, and the air-pressure drop influences the power consumption of the upstream fan or blower and thus its selection and capital cost. To fill some of these knowledge gaps, a distributed modelling method combined with the $\varepsilon-N T U$ approach has been developed in the present study based on the modelling work of Ge et al. [9,12]. After validation against test results, the modelling is employed to extensively investigate the thermohydraulic performance of two finned-tube $\mathrm{sCO}_{2}$ gas coolers and demonstrate the local interactions between the refrigerant and air-side heat transfer and the influence of design and operating parameters on the local and overall performance. The outputs of the present work can provide practical guidance for the design of finned-tube gas coolers. The present modelling approach can also be used as the basis for the modelling of integrated $\mathrm{sCO}_{2}$ refrigeration and heat-pump systems.

\section{Methodology}

The two typical finned-tube gas coolers investigated in this study are shown in Figure 1: Gas cooler A has 3 tube rows with 8 tubes per row, and gas cooler B has 2 tube rows and 16 tubes per row. The high-pressure $\mathrm{sCO}_{2}$ flows inside the copper coils, and the lower-temperature low-pressure cooling air crosses the finned tubes. The thickness of the wavy aluminum fins is $0.16 \mathrm{~mm}$ and the 
fin spacing is $2.12 \mathrm{~mm}$. In this figure, $i, j$, and $k$ represent the longitudinal, transverse, and vertical directions, respectively.
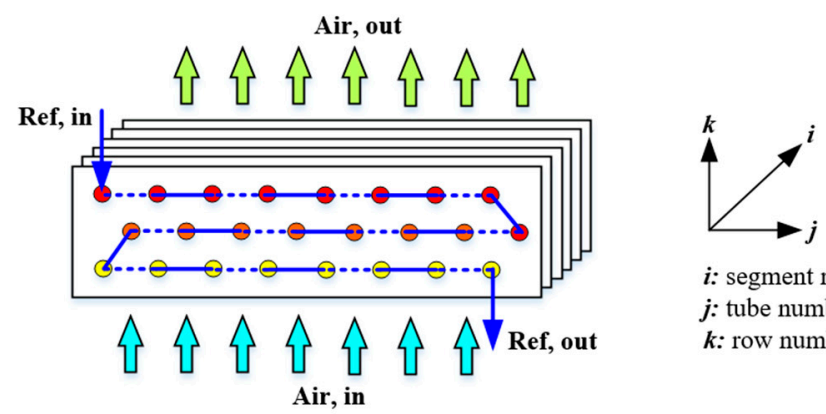

$i$ : segment number of each tube $j$ : tube number of each row $k$ : row number

(a) Gas cooler $A$

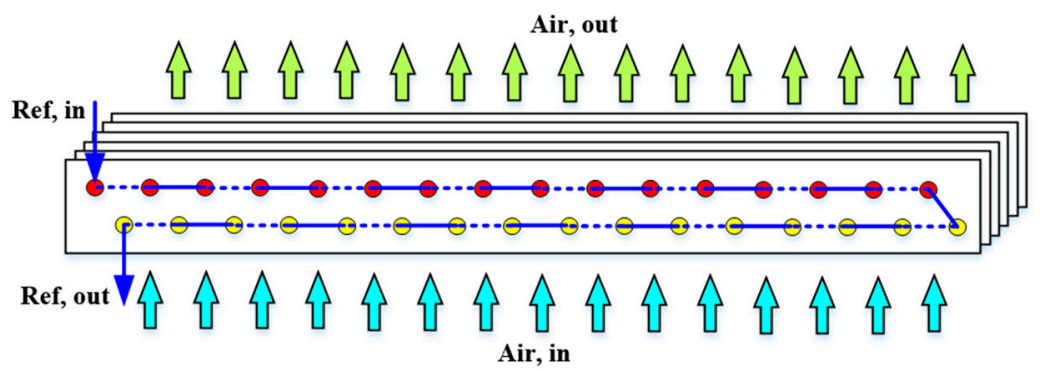

(b) Gas cooler B

Figure 1. Models of finned-tube $\mathrm{sCO}_{2}$ gas coolers: (a) gas cooler $\mathrm{A}$ and (b) gas cooler $\mathrm{B}$.

To accurately predict the thermohydraulic performance, a distributed approach was used to model the gas coolers. As shown in Figure 2, each tube of the gas cooler is evenly separated into $N=20$ segments along the refrigerant flow direction. Each segment is assumed to be a crossflow heat exchanger: The temperature and pressure of $\mathrm{sCO}_{2}$ and cooling air are determined by the energy balance and fluid-friction characteristics; and the heat transfer and fluid flow process is controlled by the $\varepsilon$-NTU method [16]. Due to the rapidly varying thermophysical properties of $\mathrm{sCO}_{2}$ in the near-critical region, the temperature- and pressure-dependent properties were obtained from the NIST REFPROP v9.1 database (National Institute of Standards and Technology, Gaithersburg, Maryland, United States). During the modelling, the gas cooler operated under the steady state condition, heat losses to or from the surroundings were neglected, heat conduction along the coil axis and within the fins were negligible.

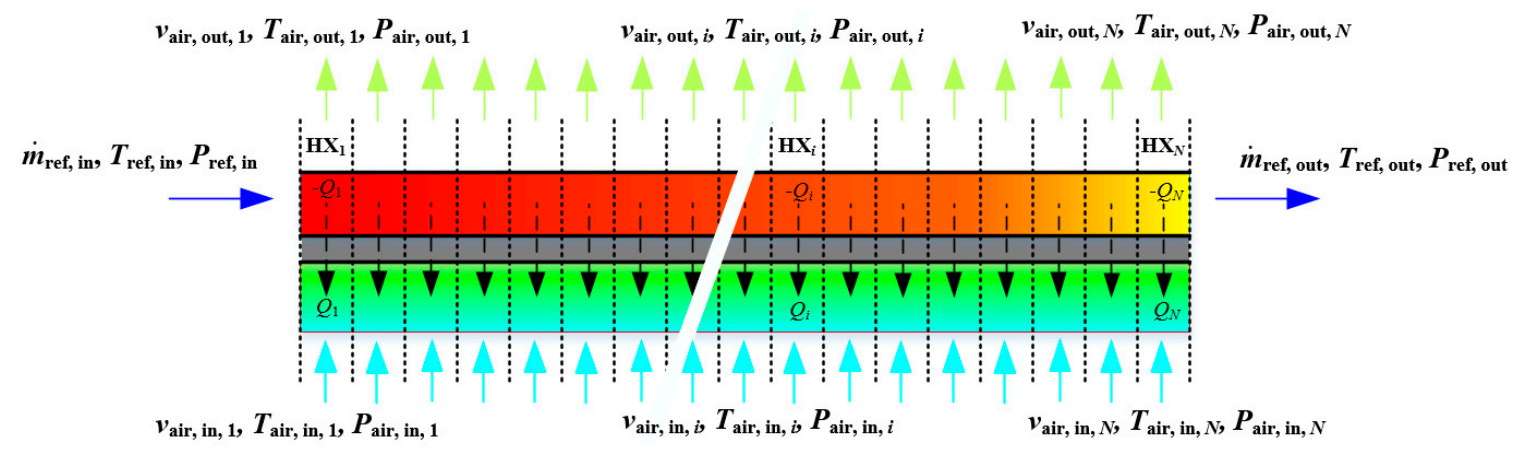

Figure 2. Segment by segment design for single tube with cross flow.

For a given segment $i$, the heat-transfer rate from the refrigerant to the cooling air is expressed as,

$$
Q_{i}=\varepsilon_{i} C_{\mathrm{min}, i}\left(T_{\mathrm{ref}, i}-T_{\mathrm{air}, i}\right)
$$


where $Q$ is the heat-transfer rate, $\varepsilon$ is the heat-exchanger effectiveness, $C$ is the capacity rate, $T_{\text {ref }}$ and $T_{\text {air }}$ are the temperatures of refrigerant and cooling air, respectively.

$$
\varepsilon_{i}=\frac{1-\exp \left[-N T U_{i}\left(1-C_{i}^{*}\right)\right]}{1-C_{i}^{*} \exp \left[-N T U_{i}\left(1-C_{i}^{*}\right)\right]}
$$

where NTU is the number of transfer units,

$$
\begin{gathered}
N T U_{i}=\frac{U_{i} A_{i}}{C_{\mathrm{min}, i}} \\
C_{i}^{*}=\frac{C_{\mathrm{min}, i}}{C_{\mathrm{max}, i}} \\
C_{\mathrm{min}, i}=\min \left(\dot{m}_{\mathrm{air}, i} C_{\mathrm{p}, \mathrm{air}, i}, \dot{m}_{\mathrm{ref}, i} C_{\mathrm{p}, \mathrm{ref}, i}\right) \\
C_{\mathrm{max}, i}=\max \left(\dot{m}_{\mathrm{air}, i} C_{\mathrm{p}, \mathrm{air}, i}, \dot{m}_{\mathrm{ref}, i} C_{\mathrm{p}, \mathrm{ref}, i}\right)
\end{gathered}
$$

where $U$ is the overall heat-transfer coefficient,

$$
U_{i} A_{i}=\frac{1}{\frac{1}{h_{\mathrm{ref}, i} A_{\mathrm{ref}, i}}+R_{\mathrm{t}, i}+\frac{1}{h_{\mathrm{air}, i} A_{\mathrm{air}, i} \eta_{\mathrm{aar}, i}}}
$$

where $h_{\text {ref }}$ and $h_{\text {air }}$ denote the heat-transfer coefficients and $A_{\text {ref }}$ and $A_{\text {air }}$ represent the heat-transfer areas, respectively, in the refrigerant and cooling air sides. $R_{\mathrm{t}}$ is the thermal resistance through the copper coils.

The heat transfer and pressure drop of the refrigerant are calculated using the empirical correlations for Nusselt number and friction factor. Considering the $\mathrm{sCO}_{2}$ properties near the critical region, the refrigerant-side heat transfer and friction factor correlations selected for the modelling was proposed by Krasnoshchekov et al. [17],

$$
\begin{gathered}
N u_{\mathrm{ref}, i}=N u_{0, i}\left(\frac{\rho_{\mathrm{w}, i}}{\rho_{\mathrm{ref}, i}}\right)^{n}\left(\frac{\overline{c_{\mathrm{p}, \mathrm{ref}, i}}}{c_{\mathrm{p}, \mathrm{w}, i}}\right)^{m} \\
N u_{0, i}=\frac{\left(f_{\mathrm{ref}, i} / 8\right)\left(R e_{\mathrm{ref}, i}-1000\right) P r_{\mathrm{ref}, i}}{1+12.7\left(f_{\mathrm{ref}, i} / 8\right)^{1 / 2}\left(P r_{\mathrm{ref}, i}^{2 / 3}-1\right)} \\
f_{\mathrm{ref}, i}=\left(0.790 \ln R e_{\mathrm{ref}, i}-1.64\right)^{-2} \\
\overline{c_{\mathrm{p}, \mathrm{ref}, i}}=\frac{h_{\mathrm{ref}, i}-h_{\mathrm{w}, i}}{T_{\mathrm{ref}, i}-T_{\mathrm{w}, i}} \\
m=B\left(\frac{\overline{c_{\mathrm{p}, \mathrm{ref}, i}}}{c_{\mathrm{p}, \mathrm{w}, i}}\right)^{s} \\
R e_{\mathrm{ref}, i}=\frac{G_{\mathrm{ref}} D_{\mathrm{o}}}{\mu_{\mathrm{ref}, i}}
\end{gathered}
$$

where $n=0.38, B=0.75$, and $s=0.18$ for $\mathrm{sCO}_{2}$ pressure near $80 \mathrm{bar}$, and $n=0.54, B=0.85$, and $s=0.104$ for $\mathrm{sCO}_{2}$ pressure near 85 bars. Fang and $\mathrm{Xu}$ [18] compared data from 297 heat-transfer experiments of $\mathrm{sCO}_{2}$ cooling in horizontal circular tubes and covering tube diameters ranging from 1.1 to $7.75 \mathrm{~mm}$ from six papers with the existing heat-transfer correlations and found that the correlation of Krasnoshchekov et al. [17] showed the best agreement. It should be noted that in vertical tubes, the effects of buoyancy on heat transfer is much more significant for $\mathrm{sCO}_{2}$ than for horizontal tubes due to axial density gradients, radial differences in viscosity, and rapid changes in density in the flow. Jackson et al. [19], Bourke et al. [20], Liao and Zhao [21], Pidaparti et al. [22], and Jiang et al. [23-25] 
have pointed out that the buoyancy effects were significant for both upward and downward flow of $\mathrm{sCO}_{2}$ at Reynolds numbers up to $10^{5}$, and the heat-transfer coefficient should include these important effects. For the vertical tubes, the correlation of Krasnoshchekov et al. [17] may not be applicable.

The thermal resistance associated with the conduction of heat through the copper coil is calculated from,

$$
R_{\mathrm{t}, i}=\frac{1}{2 \pi k_{\mathrm{t}}(L / N)} \ln \left(\frac{D_{\mathrm{o}}}{D_{\mathrm{i}}}\right)
$$

where $L$ is the length of a single tube, $D_{\mathrm{o}}$ and $D_{\mathrm{i}}$ denote the outside and inside coil diameter, respectively.

The air-side heat-transfer coefficient and pressure drop are described by the Colburn $j$ factor and Darcy $f$ factor, respectively. Wang's correlations [26] have been widely adopted for prediction of air-side performance of slit finned-tube heat exchangers and are also used in this study,

$$
\begin{gathered}
j_{\text {air }, i}=\left\{\begin{array}{c}
0.9047 R e_{\text {Dc, air, } i}^{j 1}\left(\frac{F_{\mathrm{s}}}{D_{\mathrm{c}}}\right)^{j 2}\left(\frac{P_{\mathrm{t}}}{p_{\mathrm{l}}}\right)^{j 3}\left(\frac{S_{\mathrm{s}}}{S_{\mathrm{h}}}\right)^{-0.0305} N_{\mathrm{r}}^{0.0782} \text { for } N_{\mathrm{r}}>2 \text { and } R e_{\mathrm{Dc}, \text { air }, i}<700 \\
1.0691 R e_{\mathrm{Dc}, \text { air }, i}^{j 4}\left(\frac{F_{\mathrm{s}}}{D_{\mathrm{c}}}\right)^{j 5}\left(\frac{S_{\mathrm{s}}}{S_{\mathrm{h}}}\right)^{j 6} N_{\mathrm{r}}^{j 7} \text { for } N_{\mathrm{r}}=1,2 \text { or } N_{\mathrm{r}}>2 \text { and } R e_{\mathrm{Dc}, \text { air }, i}>700
\end{array}\right. \\
f_{\mathrm{air}, i}=1.201 R e_{\mathrm{Dc}, \text { air, }, i}^{f 1}\left(\frac{F_{\mathrm{s}}}{D_{\mathrm{c}}}\right)^{f 2}\left(\frac{P_{\mathrm{t}}}{p_{\mathrm{l}}}\right)^{f 3}\left(\frac{S_{\mathrm{s}}}{S_{\mathrm{h}}}\right)^{f 4} N_{\mathrm{r}}{ }^{f 5} S_{\mathrm{n}}{ }^{f 6}
\end{gathered}
$$

where $j 1-j 7, f 1-f 7$ are correlation parameters related to the slit fin geometry, $D_{\mathrm{c}}, F_{\mathrm{s}}, P_{\mathrm{t}}, P_{1}, S_{\mathrm{s}}, S_{\mathrm{h}}, N_{\mathrm{r}}, S_{\mathrm{n}}$ are the fin collar outside diameter, fin spacing, transverse tube pitch, longitudinal tube pitch, breadth of a slit in the direction of airflow, height of slit, number of tube rows, and number of slits in an enhanced zone, respectively.

The fin efficiency is calculated by the approximation method described by Schmidt [27],

$$
\begin{gathered}
\eta_{\mathrm{air}, i}=1-\frac{A_{\mathrm{f}, i}}{A_{\mathrm{air}, i}}\left(1-\eta_{\mathrm{f}, i}\right) \\
\eta_{\mathrm{f}, i}=\frac{\tanh (m r \phi)}{m r \phi} \\
m=\sqrt{\frac{2 h_{\mathrm{air}, i}}{k_{\mathrm{f}} \delta_{\mathrm{f}}}} \\
\phi=\left(\frac{R_{\mathrm{eq}}}{r}-1\right)\left[1+0.35 \ln \left(\frac{R_{\mathrm{eq}}}{r}\right)\right] \\
\frac{R_{\mathrm{eq}}}{r}=1.27 \frac{X_{\mathrm{M}}}{r}\left(\frac{X_{\mathrm{L}}}{X_{\mathrm{M}}}-0.3\right)
\end{gathered}
$$

where $A_{\mathrm{f}}$ and $A_{\text {air }}$ represent, respectively, the fin surface area and total surface area in the air side, $\delta_{\mathrm{f}}$ is the fin thickness, $R_{\mathrm{eq}}$ and $r$ are, respectively, the equivalent radius for fin and tube inside radius, $X_{\mathrm{L}}$ and $X_{\mathrm{M}}$ are geometric parameters related to $P_{\mathrm{t}}$ and $P_{1}$.

Due to the dependence of the refrigerant-side heat-transfer correlation on the inside tube wall temperature, a solving routine for each segment starts from a wall temperature just a little lower than the refrigerant $\left(T_{\mathrm{wi}, i}=T_{\text {ref, } i}-0.002\left(T_{\mathrm{ref}, i}-T_{\mathrm{air}, \mathrm{i}}\right)\right)$ and then computes with a step-by-step decreased wall temperature $\left(T_{\mathrm{wi}, i}=T_{\mathrm{wi}, i}-0.002\left(T_{\mathrm{ref}, i}-T_{\mathrm{air}, \mathrm{i}}\right)\right.$ to obtain the heat transfer of $\mathrm{sCO}_{2}$ to the cooling air. This solving routine stops when the difference between the heat-transfer rates calculated on the $\mathrm{sCO}_{2}$ and cooling air sides become lower than $2 \%$.

In the modelling, only the inlet properties of refrigerant and cooling air in the gas cooler are known, and all the outlet properties must be calculated. To obtain these outlet properties for the cross flows, two other solving routines are employed: the inside iteration for the refrigerant temperature and the outside one for the refrigerant pressure. For the temperature iteration, the solving routine starts from an assumed refrigerant outlet temperature close to the cooling air inlet temperature and 
then iterates with the gradually increased outlet temperature until the calculated refrigerant inlet temperature matches the designated value. For the pressure iteration, an assumed refrigerant outlet pressure just a little lower than the inlet launches the solving routine and then little-by-litter the decreased outlet pressure iterates to make the calculated inlet pressure approach the given value. Keep in mind that each assumption of refrigerant outlet pressure contains one iteration routine of temperature calculation.

The obtained parameters at the inlet of each segment for the refrigerant are used as the outlet parameters for the next segment. For the next segment $i+1$, the outlet temperature and pressure of the refrigerant are calculated as,

$$
\begin{gathered}
T_{\text {ref }, i+1}=T_{\text {ref }, i}+\frac{Q_{i}}{\dot{m}_{\text {ref }, i} c_{\mathrm{p}, \text { ref }, i}} \\
p_{\text {ref }, i+1}=p_{\text {ref }, i}+\Delta p_{\text {ref }, i}
\end{gathered}
$$

The obtained parameters at the outlet of each segment for the cooling air are used as the inlet parameters for the next tube row. For the next tube row $k-1$, the inlet temperature and pressure of the cooling air are calculated as,

$$
\begin{gathered}
T_{\text {air,in }, i, k-1}=T_{\text {air,in }, i, k}+\frac{Q_{i k}}{\dot{m}_{\mathrm{air}, i, k} c_{\mathrm{p}, \mathrm{air}, i, k}} \\
p_{\text {air, in }, i, k-1}=p_{\mathrm{air}, \mathrm{in}, i, k}-\Delta p_{\mathrm{air}, i, k}
\end{gathered}
$$

Since the density of $\mathrm{sCO}_{2}$ undergoes a dramatic change with temperature decrease in the near-critical region, the pressure drop $\Delta p_{\text {ref, I }}$, considering the deceleration along the flow direction, can be determined from:

$$
\Delta p_{\mathrm{ref}, i}=\frac{f_{\mathrm{ref}, i} G_{\mathrm{ref}}^{2} L}{2 \rho_{\mathrm{ref}, i} D N}-\frac{G_{\mathrm{ref}}^{2}}{2 \rho_{\mathrm{ref}, i}}+\frac{G_{\mathrm{ref}}^{2}}{2 \rho_{\mathrm{ref}, i+1}}
$$

For the accurate calculation of air-side pressure drop, the pressure drop $\Delta p_{\mathrm{air}, \mathrm{i}}$ also contains the influence of flow acceleration due to density change with temperature,

$$
\Delta p_{\text {air }, i}=\frac{f_{\text {air }, i} G_{\text {air }}^{2} L}{2 \rho_{\text {air }, \text { in }, i} D N}+\frac{G_{\text {air }}^{2}}{2 \rho_{\text {air }, \text { in }, i}}-\frac{G_{\text {air }}^{2}}{2 \rho_{\text {air }, \text { out }, i}}
$$

Based on the above equations and assumptions, the modelling code was written in the MATLAB programming language (The MathWorks Inc, Natick, Massachusetts, United States). A flow chart of the modelling procedure is shown in Figure 3. 


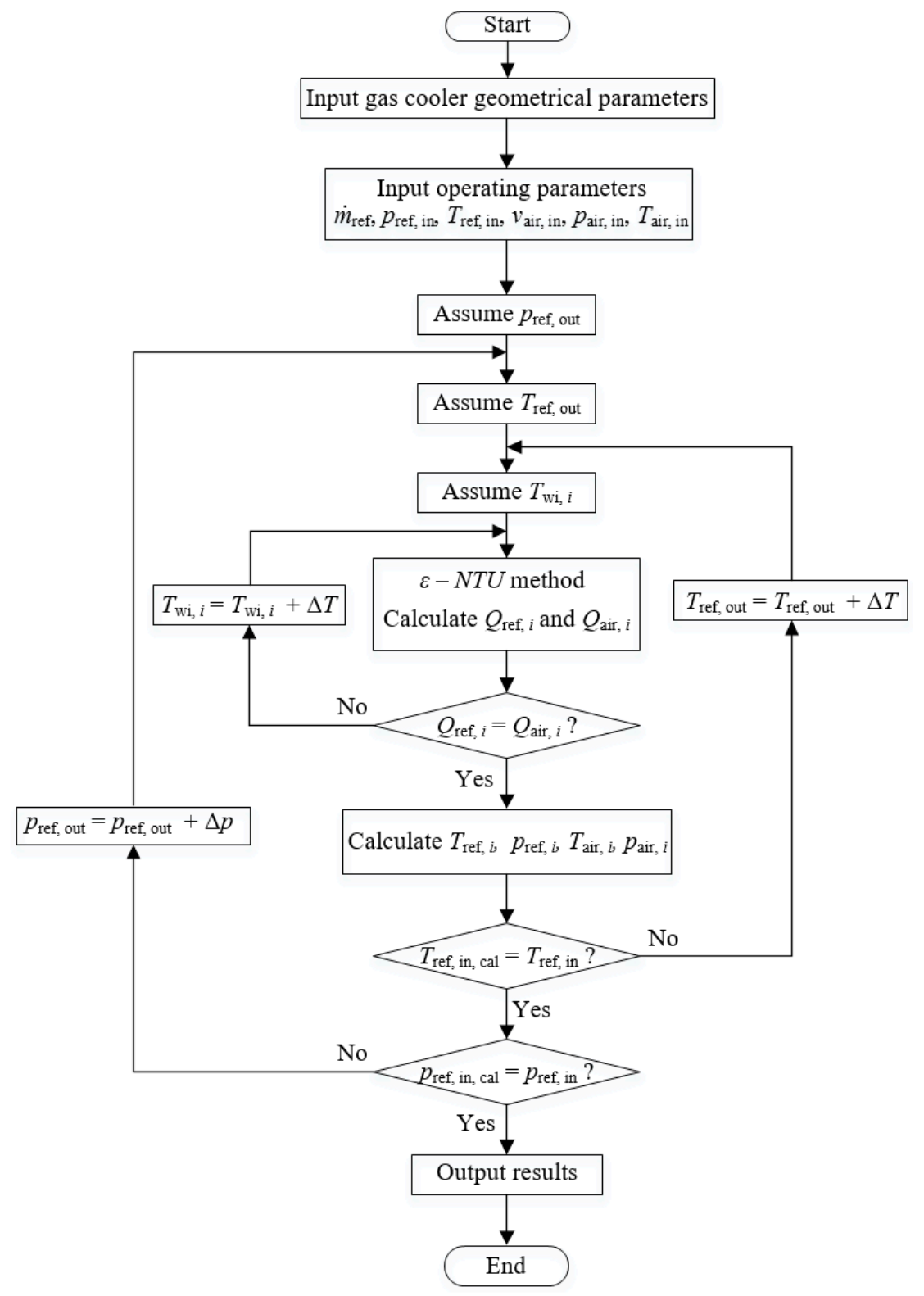

Figure 3. Flowchart for the modelling of the gas coolers.

\section{Model Validation}

To examine the thermohydraulic performance of $\mathrm{sCO}_{2}$ gas coolers of different sizes and operating conditions, a test facility was developed in the RCUK (Research Councils UK) Centre for Sustainable Energy Use in Food Chains, Brunel University London. As shown in Figure 4, the test rig allows uniformly distributed air velocity and controlled air inlet temperature and flow rate. It is also comprehensively instrumented with two thermocouple meshes with 24 measurement points each for the air-in and air-out temperatures, pressure differences of air flow through the gas cooler to ascertain the air-side pressure drop, and average air-flow velocity to obtain the air-flow rate. The detailed test facility description can be found in $[9,11]$. 


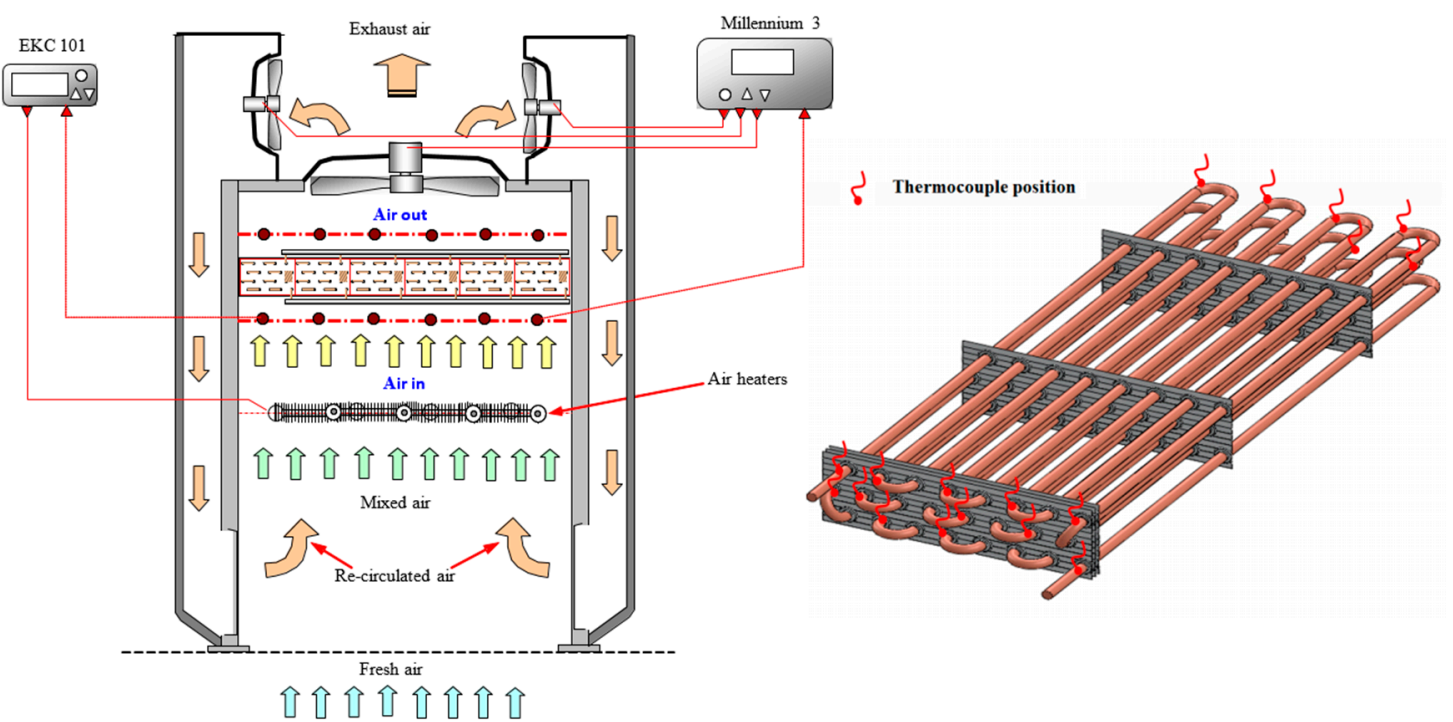

Figure 4. Gas cooler test rig and thermocouple positions.

To prove the validity of the proposed modelling methodology, a comparison between the modelling predictions and the experimental results from Santosa et al. [11] is illustrated in Table 1. Considering the uncertainty of the K-type thermocouples and pressure transducers used in the test facility, the present modelling can predict the thermohydraulic performance of the gas coolers with a good accuracy, although the relative uncertainty between the calculated and experimental value of air-side pressure drop is a little high in some cases. Taking into account the uncertainty of the air-side pressure drop sensor (differential pressure transducer KIMO CP 200 (Sauermann group, Montpon-Ménestérol, France), measuring range $0-80 \mathrm{~Pa}$ with accuracy $\pm 1 \%$ ) and the not perfectly uniform distribution of cooling-air velocity, the calculated results can be considered acceptable. To verify the local performance, comparison of the refrigerant temperature profile along the refrigerant flow direction $(x)$ between the modelling predictions and test results is shown in Figure 5 for the six tests listed in Table 1. Similar results again demonstrate the accuracy of the proposed modelling.

Table 1. Comparison of modelling results with experimental data [11].

\begin{tabular}{|c|c|c|c|c|c|c|c|c|}
\hline \multicolumn{9}{|c|}{ Operating Conditions } \\
\hline Test & $\begin{array}{l}v_{\text {air, in }} \\
(\mathrm{m} / \mathrm{s})\end{array}$ & $\begin{array}{c}T_{\text {air, in }} \\
\left({ }^{\circ} \mathrm{C}\right)\end{array}$ & $\begin{array}{c}p_{\text {ref, in }} \\
\text { (bar) }\end{array}$ & $\begin{array}{c}T_{\text {ref, in }} \\
\left.\text { ( }{ }^{\circ} \mathrm{C}\right)\end{array}$ & $\begin{array}{l}\dot{m}_{\mathrm{ref}} \\
(\mathrm{g} / \mathrm{s})\end{array}$ & $R e_{\mathrm{Dc}, \text { air, in }}$ & $R e_{\text {ref, in }}$ & \\
\hline & \multicolumn{8}{|c|}{ Gas Cooler A } \\
\hline No. 1 & 1.7 & 32.8 & 85.1 & 105.5 & 10.5 & 1373 & 96,764 & \\
\hline No. 2 & 2.0 & 32.8 & 84.2 & 99.2 & 10 & 1615 & 92,595 & \\
\hline \multirow[t]{2}{*}{ No. 3} & 2.4 & 34.3 & 86.6 & 116.8 & 10.3 & 1921 & 93,345 & \\
\hline & \multicolumn{8}{|c|}{ Gas Cooler B } \\
\hline No. 4 & 1.7 & 35.1 & 86.3 & 100.8 & 19 & 1355 & 17,468 & \\
\hline No. 5 & 2.0 & 35.2 & 86.5 & 104.6 & 21.5 & 1593 & 19,678 & \\
\hline No. 6 & 2.4 & 33.0 & 83.9 & 101.3 & 21 & 1936 & 19,375 & \\
\hline \multicolumn{9}{|c|}{ Results } \\
\hline Test & $\begin{array}{c}\Delta p_{\text {air, exp }} \\
\quad(\mathrm{Pa})\end{array}$ & $\underset{(\mathbf{P a})}{\Delta p_{\text {air, mod }}}$ & $\begin{array}{l}T_{\text {ref, out, exp }} \\
\quad \text { ( } \mathrm{C} \text { ) }\end{array}$ & $\begin{array}{l}T_{\text {ref, out, mod }} \\
\quad \text { ( } \mathrm{C})\end{array}$ & $\begin{array}{l}T_{\text {air, out, exp }} \\
\text { ('C) }\end{array}$ & $\begin{array}{l}T_{\text {air, out, mod }} \\
\text { ( } \mathrm{C})\end{array}$ & $\begin{array}{l}Q_{\exp } \\
(\mathrm{kW})\end{array}$ & $\begin{array}{c}Q_{\text {mod }} \\
(\mathbf{k W})\end{array}$ \\
\hline & \multicolumn{8}{|c|}{ Gas Cooler A } \\
\hline No. 1 & 26.6 & 26.9 & 33.2 & 32.83 & 36.9 & 36.8 & 2.4 & 2.46 \\
\hline No. 2 & 34.2 & 34.8 & 32.8 & 32.82 & 35.9 & 36.0 & 2.23 & 2.31 \\
\hline \multirow[t]{2}{*}{ No. 3} & 41.4 & 46.6 & 34.9 & 34.31 & 37.2 & 37.1 & 2.4 & 2.43 \\
\hline & \multicolumn{8}{|c|}{ Gas Cooler B } \\
\hline No. 4 & 13.9 & 17.6 & 35.3 & 35.38 & 38.7 & 38.5 & 4.1 & 4.12 \\
\hline No. 5 & 25.6 & 22.7 & 35.0 & 35.54 & 38.5 & 38.5 & 4.6 & 4.75 \\
\hline No. 6 & 27.6 & 30.4 & 33.0 & 33.15 & 35.9 & 35.9 & 4.65 & 4.94 \\
\hline
\end{tabular}




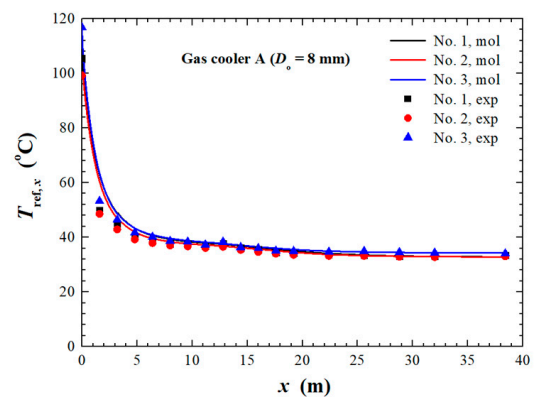

(a)

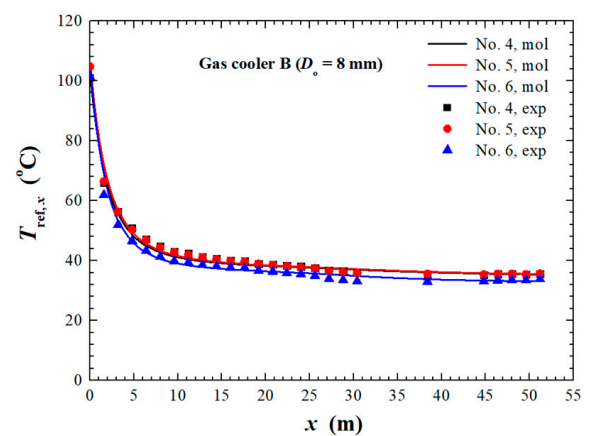

(b)

Figure 5. Comparison of the temperature profiles along the refrigerant flow direction between the modelling predictions and test results: (a) for the 3-row gas cooler A and (b) for the 2-row gas cooler B.

\section{Results}

\subsection{Local Thermohydraulic Performance}

The local thermohydraulic performance of finned-tube gas coolers is influenced by the tube and fin structures and arrangement and by the operating conditions of working fluids flowing through or across the tubes. Due to the testing difficulty, the distributed approach was used to obtain local data in the present study. The two gas coolers tested by Santosa et al. [11] were selected. The copper coils had $8 \mathrm{~mm}$ outer diameter, $0.68 \mathrm{~mm}$ wall thickness, and $1.6 \mathrm{~m}$ length, and the tube spacings in the $j$ direction $S_{j}$ and in the $k$ direction $S_{k}$ were $25.4 \mathrm{~mm}$ and $22 \mathrm{~mm}$, respectively. The operating conditions of No. 3 and No. 6 listed in Table 1 were chosen to demonstrate the local heat-transfer and pressure-drop characteristics of both $\mathrm{sCO}_{2}$ and cooling air along the $x$ direction.

Figure 6 illustrates the local heat-transfer performance of the gas coolers. In Figure 6a it can be seen that the heat-transfer coefficient of $\mathrm{sCO}_{2}$ increases along the $x$ direction until the maximum is reached as the bulk fluid temperature decreases to just above the pseudocritical temperature (the temperature corresponding to the specific heat peak at pressures above the critical point [28]) presented in Figure $6 b$, and then decreases. Further, the larger mass flow rate of No. 6 results in a much larger $\mathrm{sCO}_{2}$ heat-transfer coefficient than No. 3. In addition, the heat-transfer coefficients of the vertically upward flowing air are one or two orders of magnitude lower than those of $\mathrm{sCO}_{2}$, clearly indicating the most thermal resistance lies on the air side. The finned tubes at the bottom of the gas cooler also have higher heat-transfer coefficients than those at the top. As displayed in Figure $6 \mathrm{~b}$, about $90 \%$ of the overall temperature drop of the $\mathrm{sCO}_{2}$ takes place in the first $10 \mathrm{~m}$, mainly due to the large temperature difference between the refrigerant and air sides as illustrated in Figure $6 c$, and the temperatures of cooling air jumps from one tube row to another after absorbing the heat. As demonstrated in Figure $6 c$, the local temperature difference and the local heat-transfer gradient have similar variation patterns, demonstrating that the temperature difference has a significant impact on the heat-transfer process in the gas cooler.

Figure 7 shows the local hydraulic performance. The friction factors of $\mathrm{sCO}_{2}$ continuously climb up along the flow direction and then remain stable, corresponding to the variation of fluid temperatures shown in Figure 6b. These variations are determined by the change of Reynold number in accordance with Equation (10), which is contingent on the temperature-dependent and pressure-dependent thermophysical properties. In addition, the larger mass flow rate for No. 6 results in a lower friction factor than that of No. 3. For the cooling air flow, the friction factors are mainly determined by the tube row, where the first bottom row shows lower friction factors than the upper rows, and the friction factors in the same tube row present almost similar values. Figure $7 \mathrm{~b}$ reveals that larger mass flow rate and longer flow length for No. 6 cause a dramatic increase in pressure drop of $\mathrm{sCO}_{2}$ than that of No. 3 , which will require the compressor to consume more electricity power for operation. More tube rows of No. 3 bring about more pressure drop of cooling air than that of No. 6, which will demand an air 
fan with higher discharge pressure. Figure $7 \mathrm{c}$ shows the corresponding variations of local Reynolds number for both $\mathrm{sCO}_{2}$ and cooling air.

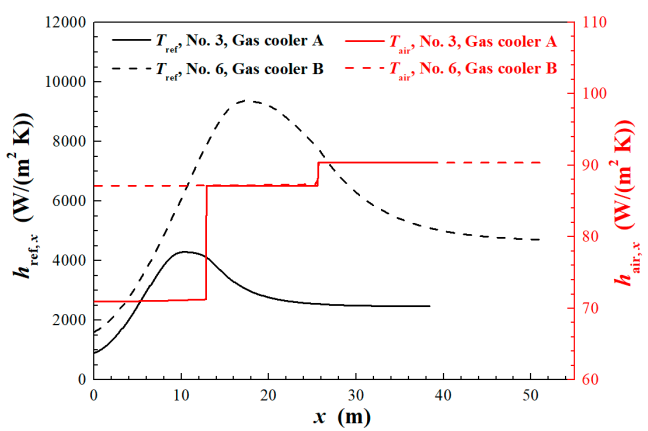

(a)

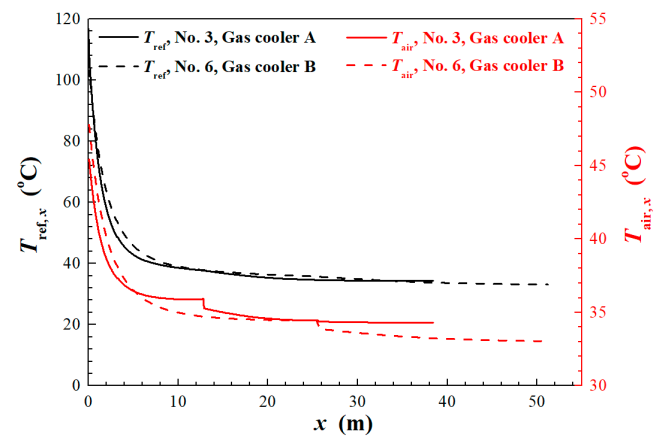

(b)

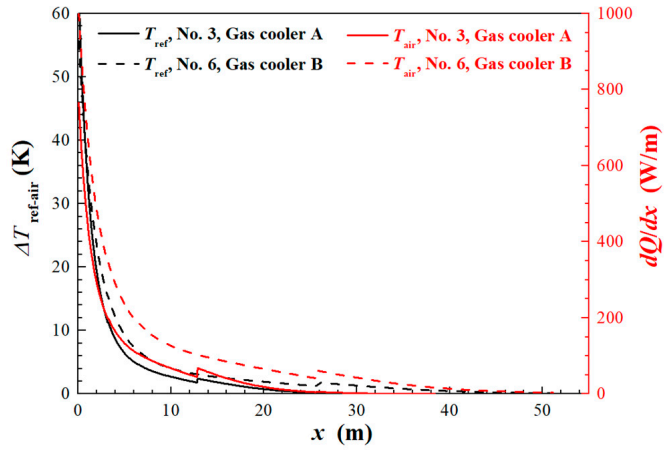

(c)

Figure 6. Local heat-transfer performance of $\mathrm{sCO}_{2}$ and air: (a) heat-transfer coefficient; (b) temperature and (c) temperature difference and heat-transfer gradient.

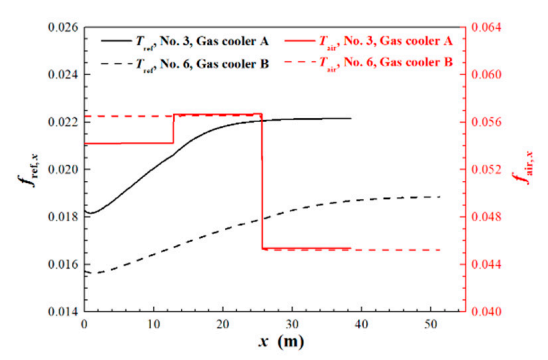

(a)

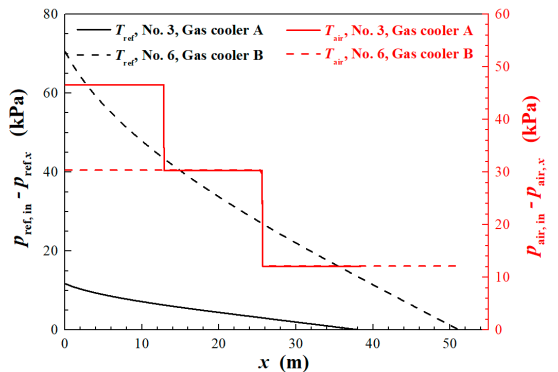

(b)

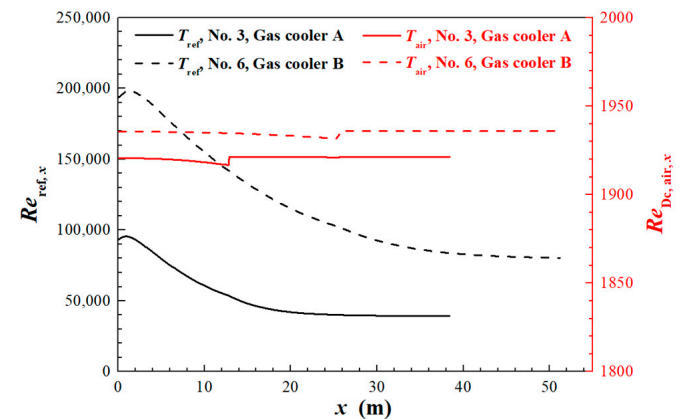

(c)

Figure 7. Local hydraulic performance of $\mathrm{sCO}_{2}$ and air: (a) friction factor; (b) pressure drop, and (c) Reynolds number. 


\subsection{Influence of Refrigerant Mass Flow Rate}

Increasing in the refrigerant mass flow rate usually improves the refrigerant heat-transfer coefficient and heat rejection and can reduce the size of the gas cooler for a given cooling capacity. However, as shown in Figure 7, the larger mass flow rate also yields a much higher pressure drop. Furthermore, the excess refrigerant mass can result in the inlet temperature of the compressor being larger than its requirement, making the lubricating oils lose their effectiveness and be discharged by the compressor along with the refrigerant, which can exert a very adverse effect on heat transfer and pressure drops $[29,30]$. To investigate these influences, the operating conditions were selected as follows: all parameters except the $\mathrm{sCO}_{2}$ mass flow rate were kept the same as No. 3 for gas cooler A and No. 6 for gas cooler B listed in Table $1\left(v_{\text {air, in }}=2.4 \mathrm{~m} / \mathrm{s}, T_{\text {air, in }}=34.3^{\circ} \mathrm{C}, p_{\text {ref, in }}=86.6 \mathrm{bar}, T_{\text {ref, in }}=116.8^{\circ} \mathrm{C}\right.$ for gas cooler $\mathrm{A}$, and $v_{\text {air, in }}=2.4 \mathrm{~m} / \mathrm{s}, T_{\text {air, in }}=33^{\circ} \mathrm{C}, p_{\text {ref, in }}=83.9 \mathrm{bar}, T_{\text {ref, in }}=101.3{ }^{\circ} \mathrm{C}$ for gas cooler $\mathrm{B}$ ). The studied mass flow rates were up to three times those of No. 3 for gas cooler A and double those of No. 6 for gas cooler B, with $20 \%$ intervals.

Figures 8-10 indicate the influence of refrigerant mass flow rate on the performance of gas cooler A. As shown in Figure 8, the outlet temperature of $\mathrm{sCO}_{2}$ continuously rises with increasing mass flow rate and the same variation for outlet temperature of air due to the energy balance. The outlet temperature of air is the mass-weighted-average value after the gas cooler. Tripling the refrigerant mass flow rate increases the $\mathrm{sCO}_{2}$ outlet temperature from $34.3^{\circ} \mathrm{C}$ to $36.7^{\circ} \mathrm{C}$, and the air outlet temperature from 37.1 ${ }^{\circ} \mathrm{C}$ to $42.2{ }^{\circ} \mathrm{C}$. As shown in Figure 9, the increased refrigerant mass flow rate causes a tremendously higher pressure drop in $\mathrm{sCO}_{2}$ due to the increased mass flux, as Equation (26), and a very slight increase in pressure drop of the air due to the variation of the thermophysical properties with larger temperature. With the mass flow rate varying from 10.3 to $30.9 \mathrm{~g} / \mathrm{s}$, the pressure drop of $\mathrm{sCO}_{2}$ goes up by an order of magnitude from 11.8 to $119.2 \mathrm{kPa}$, while that of air rises from 46.6 to $46.9 \mathrm{~Pa}$. Figure 10 presents the variation of heat-transfer rate and pumping power (volume flow rate by pressure drop) of $\mathrm{sCO}_{2}$ including the large increase in the heat-transfer rate from 2.43 to $6.51 \mathrm{~kW}$ and the rapid growth of the pumping power from 0.85 to $25.82 \mathrm{~W}$.

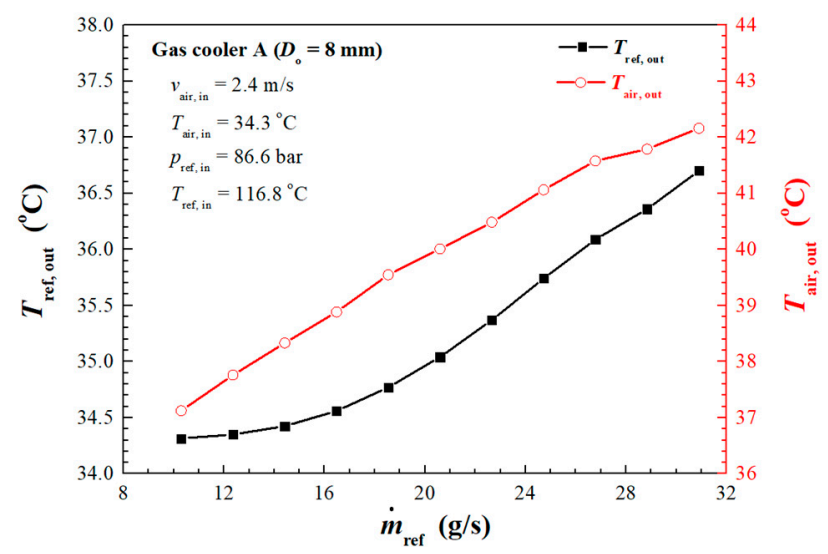

Figure 8. Influence of refrigerant mass flow rate on outlet temperature of $\mathrm{sCO}_{2}$ and air for gas cooler A. 


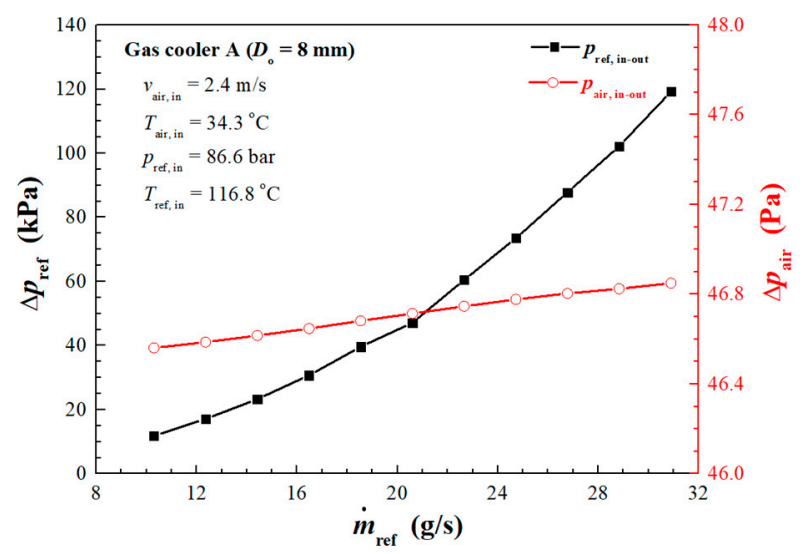

Figure 9. Influence of refrigerant mass flow rate on pressure drop of $\mathrm{sCO}_{2}$ and air for gas cooler A.

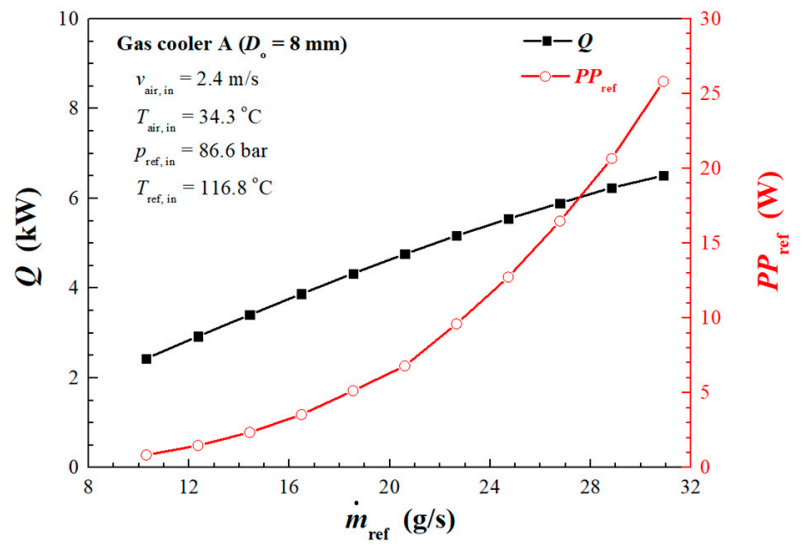

Figure 10. Influence of refrigerant mass flow rate on heat-transfer rate and $\mathrm{sCO}_{2}$ pumping power for gas cooler A.

Figures 11-13 demonstrate the performance variation of gas cooler B. Doubling the refrigerant mass flow rate leads to an outlet temperature rise from $33.2^{\circ} \mathrm{C}$ to $35.3^{\circ} \mathrm{C}$ for the $\mathrm{sCO}_{2}$ and from $35.9^{\circ} \mathrm{C}$ to $38.1^{\circ} \mathrm{C}$ for the air. The associated pressure drop increases dramatically from 70.7 to $282.4 \mathrm{kPa}$ for the $\mathrm{sCO}_{2}$ and slightly from 30.4 to $30.5 \mathrm{~Pa}$ for the air. The corresponding heat-transfer rate improves from 4.95 to $8.68 \mathrm{~kW}$ and the related pumping power of $\mathrm{sCO}_{2}$ jumps from 9.97 to $79.66 \mathrm{~W}$. It can be found that the heat-transfer rate increases nearly but not exactly linearly with the mass flow rate. This is caused mainly by the extraordinary increase of the pumping power of $\mathrm{sCO}_{2}$ and partly by the increase of outlet temperature.

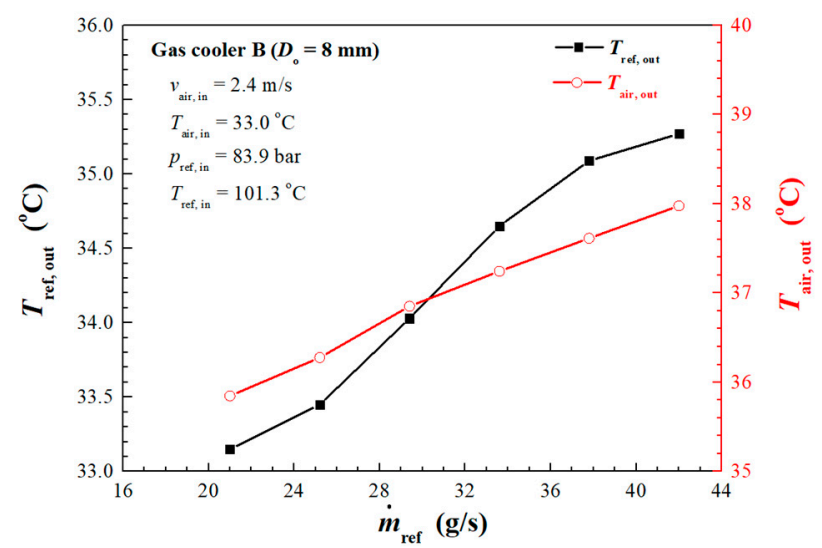

Figure 11. Influence of refrigerant mass flow rate on outlet temperature of $\mathrm{sCO}_{2}$ and air for gas cooler $\mathrm{B}$. 


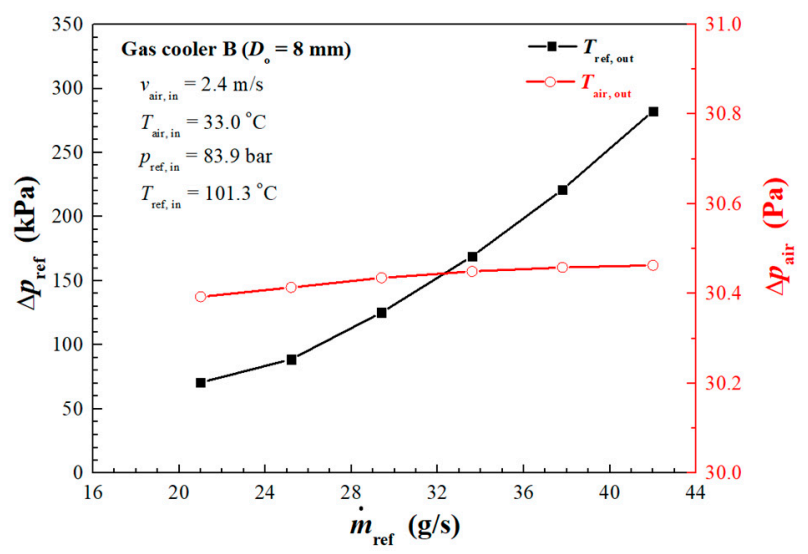

Figure 12. Influence of refrigerant mass flow rate on pressure drop of $\mathrm{sCO}_{2}$ and air for gas cooler $\mathrm{B}$.

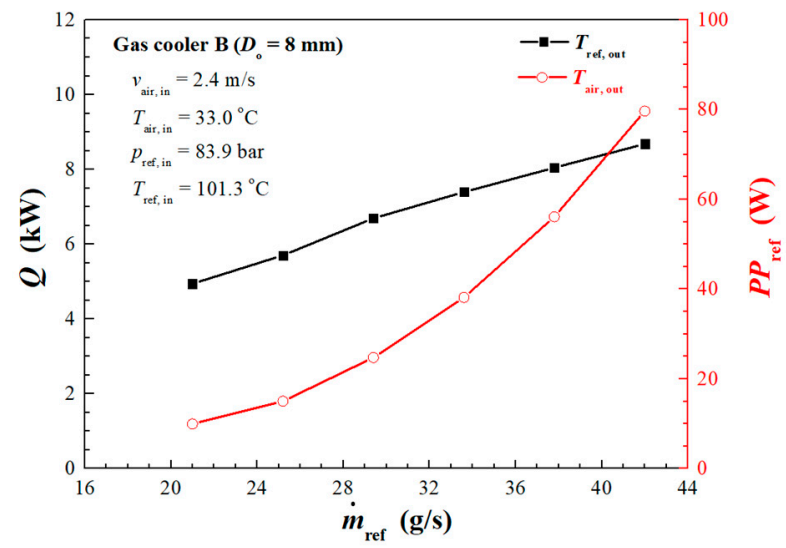

Figure 13. Influence of refrigerant mass flow rate on heat-transfer rate and $\mathrm{sCO}_{2}$ pumping power for gas cooler B.

\subsection{Comparison between $8 \mathrm{~mm}$ and $5 \mathrm{~mm}$ Coils Finned-Tube Gas Coolers}

The most common diameters of gas cooler tubes used in commercial air conditioning and heat-pump systems are generally in the range of 3-8 $\mathrm{mm}$. However, most investigations have focused on coils of about $8 \mathrm{~mm}$ diameter and comparatively few on the smaller coils; more careful work is needed for gas coolers with the smaller coils [31]. In this section, the performance of the gas cooler is compared between the $8 \mathrm{~mm}$ and $5 \mathrm{~mm}$ coils. Two types of gas coolers with $5 \mathrm{~mm}$ coils-one with $5 / 8$ shrinkage ratio of tube length and tube spacing in normal and parallel directions to the $8 \mathrm{~mm}$ coil gas cooler, and the other with 5/8 shrinkage ratio only in tube spacing-were designed, respectively, for the 3 tube rows with 8 tubes per row gas cooler $\mathrm{A}$ and 2 tube rows with 16 tubes per row gas cooler $\mathrm{B}$. The gas coolers with $5 \mathrm{~mm}$ coils have only $39.1 \%$ (for $L=1.6 \mathrm{~m}$ ) and $24.4 \%$ (for $L=1.0 \mathrm{~m}$ ) volume of those with $8 \mathrm{~mm}$ coils $(L=1.6 \mathrm{~m})$. Two types of operating condition for cooling air, one keeping the same velocity, and the other keeping the same mass flow rate, were employed. Table 2 illustrates the detailed geometry and operating conditions for comparison between $8 \mathrm{~mm}$ and $5 \mathrm{~mm}$ coils finned-tube gas coolers. The other operating parameters except the $\mathrm{sCO}_{2}$ mass flow rate were kept the same as No. 3 for gas cooler A and No. 6 for gas cooler B in Table $1\left(T_{\text {air, in }}=34.3^{\circ} \mathrm{C}, p_{\text {ref }}=86.6\right.$ bar, $T_{\text {ref, in }}=116.8$ ${ }^{\circ} \mathrm{C}, T_{\text {ref, out }}=34.31{ }^{\circ} \mathrm{C}$ for gas cooler $\mathrm{A}$, and $T_{\text {air, in }}=33.0^{\circ} \mathrm{C}, p_{\text {ref }}=83.9 \mathrm{bar}, T_{\text {ref, in }}=101.3{ }^{\circ} \mathrm{C}, T_{\text {ref, out }}$ $=33.15^{\circ} \mathrm{C}$ for gas cooler $\mathrm{B}$ ). It should be noted that in the above sections for the calculation of the 8 $\mathrm{mm}$ coil finned-tube gas coolers, the mass flow rate of the $\mathrm{sCO}_{2}$ is fixed and the outlet temperature is iterated. However, in this section when we compare the gas cooler performance between $8 \mathrm{~mm}$ and 5 $\mathrm{mm}$ coils, the outlet temperature of the $\mathrm{sCO}_{2}$ is fixed and the mass flow rate should be iterated. 
Table 2. Geometry and operating conditions for comparison between $8 \mathrm{~mm}$ and $5 \mathrm{~mm}$ coils finned-tube gas coolers.

\begin{tabular}{|c|c|c|c|}
\hline Type & No & Dimension & Operating Condition \\
\hline \multirow{5}{*}{ Gas cooler A } & 1 & $\begin{array}{c}D_{\mathrm{o}}=8 \mathrm{~mm}, D_{\mathrm{in}}=6.64 \mathrm{~mm}, S_{j}=25.4 \mathrm{~mm} \\
S_{k}=22 \mathrm{~mm}, L=1.6 \mathrm{~m}, 12 \text { fins per inch }\end{array}$ & $\begin{array}{c}v_{\text {air, in }}=2.4 \mathrm{~m} / \mathrm{s} \\
\left(\dot{m}_{\text {air, in }}=0.8794 \mathrm{~kg} / \mathrm{s}\right)\end{array}$ \\
\hline & 2 & $\begin{aligned} D_{\mathrm{o}} & =5 \mathrm{~mm}, D_{\text {in }}=4.5 \mathrm{~mm}, S_{j}=15.875 \mathrm{~mm}, \\
S_{k} & =13.75 \mathrm{~mm}, L=1.6 \mathrm{~m}, 12 \text { fins per inch }\end{aligned}$ & $v_{\text {air, in }}=2.4 \mathrm{~m} / \mathrm{s}$ \\
\hline & 3 & $\begin{aligned} D_{\mathrm{o}} & =5 \mathrm{~mm}, D_{\text {in }}=4.5 \mathrm{~mm}, S_{j}=15.875 \mathrm{~mm}, \\
S_{k} & =13.75 \mathrm{~mm}, L=1.0 \mathrm{~m}, 12 \text { fins per inch }\end{aligned}$ & $v_{\text {air, in }}=2.4 \mathrm{~m} / \mathrm{s}$ \\
\hline & 4 & Same as gas cooler A 2 & $\dot{m}_{\text {air, in }}=0.8794 \mathrm{~kg} / \mathrm{s}$ \\
\hline & 5 & Same as gas cooler A 3 & $\dot{m}_{\text {air, in }}=0.8794 \mathrm{~kg} / \mathrm{s}$ \\
\hline \multirow{5}{*}{ Gas cooler B } & 1 & $\begin{array}{c}D_{\mathrm{o}}=8 \mathrm{~mm}, D_{\mathrm{in}}=6.64 \mathrm{~mm}, S_{j}=25.4 \mathrm{~mm} \\
S_{k}=22 \mathrm{~mm}, L=1.6 \mathrm{~m}, 12 \text { fins per inch }\end{array}$ & $\begin{array}{c}v_{\text {air, in }}=2.4 \mathrm{~m} / \mathrm{s} \\
\left(\dot{m}_{\text {air, in }}=1.7662 \mathrm{~kg} / \mathrm{s}\right)\end{array}$ \\
\hline & 2 & $\begin{aligned} D_{\mathrm{o}} & =5 \mathrm{~mm}, D_{\text {in }}=4.5 \mathrm{~mm}, S_{j}=15.875 \mathrm{~mm}, \\
S_{k} & =13.75 \mathrm{~mm}, L=1.6 \mathrm{~m}, 12 \text { fins per inch }\end{aligned}$ & $v_{\text {air, in }}=2.4 \mathrm{~m} / \mathrm{s}$ \\
\hline & 3 & $\begin{aligned} D_{\mathrm{o}} & =5 \mathrm{~mm}, D_{\text {in }}=4.5 \mathrm{~mm}, S_{j}=15.875 \mathrm{~mm}, \\
S_{k} & =13.75 \mathrm{~mm}, L=1.0 \mathrm{~m}, 12 \text { fins per inch }\end{aligned}$ & $v_{\text {air, in }}=2.4 \mathrm{~m} / \mathrm{s}$ \\
\hline & 4 & Same as gas cooler B 2 & $\dot{m}_{\mathrm{air}, \text { in }}=1.7662 \mathrm{~kg} / \mathrm{s}$ \\
\hline & 5 & Same as gas cooler B 3 & $\dot{m}_{\mathrm{air}, \text { in }}=1.7662 \mathrm{~kg} / \mathrm{s}$ \\
\hline
\end{tabular}

Figures 14 and 15 illustrate the differences in performance of gas cooler A between the $8 \mathrm{~mm}$ and $5 \mathrm{~mm}$ tube coils. The heat-transfer rate of gas cooler A with $5 \mathrm{~mm}$ tubes reduces to $57.1 \%$ (for $L=1.6 \mathrm{~m}$ ) and $31.9 \%$ (for $L=1.0 \mathrm{~m}$ ) of those with $8 \mathrm{~mm}$ tubes for the same air velocity condition $v_{\text {air, in }}=2.4 \mathrm{~m} / \mathrm{s}$, and to $71.4 \%$ and $50.2 \%$ for the same air mass flow rate condition $\dot{m}_{\mathrm{air}, \text { in }}=0.8794 \mathrm{~kg} / \mathrm{s}$. Considering the heat-transfer capacity per unit volume of the gas cooler, the $5 \mathrm{~mm}$ coil shows better heat-transfer performance, particularly for the same air mass flow rate condition. However, employing smaller tubes leads to higher pressure drop and pumping power per unit length. As shown in Figure 15, for the same length $L=1.6 \mathrm{~m}$, the gas cooler A with $5 \mathrm{~mm}$ tubes results in 3.48 times larger pressure drop for $\mathrm{sCO}_{2}$ for the same air velocity condition and is 5.26 times higher under the same air mass flow rate condition. For the same air mass flow rate, the air velocity increases to 3.84 and $6.144 \mathrm{~m} / \mathrm{s}$ in the $5 \mathrm{~mm}$ tube gas cooler for the coil lengths of $L=1.6 \mathrm{~m}$ and $L=1.0 \mathrm{~m}$, respectively. The increased air velocity leads to much higher pressure drops, 93.5 and $217.2 \mathrm{~Pa}$, respectively, on the air side, compared to 46.6 $\mathrm{Pa}$ for the $8 \mathrm{~mm}$ tube coil at $46.6 \mathrm{~Pa}$.

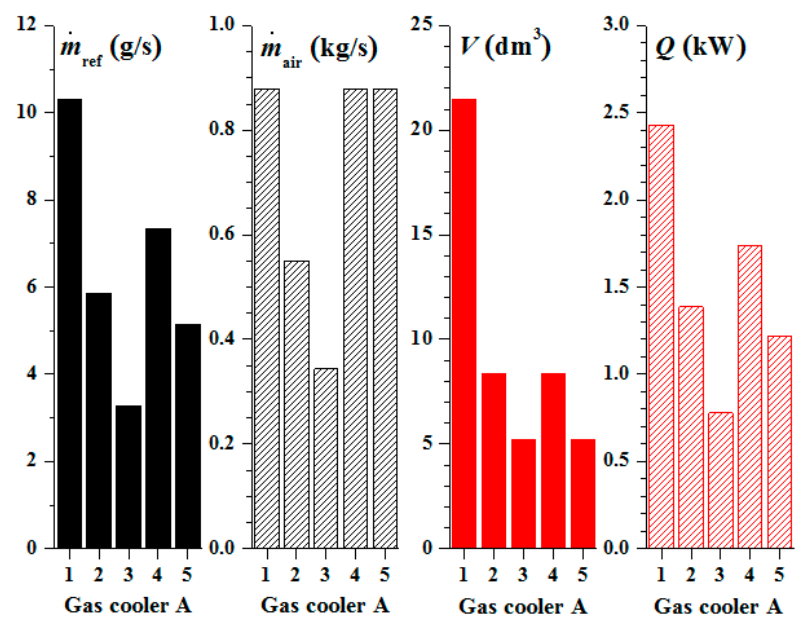

Figure 14. Comparison between $8 \mathrm{~mm}$ and $5 \mathrm{~mm}$ coils gas cooler $\mathrm{A}$ for $\dot{m}_{\text {ref }}, \dot{m}_{\text {air }}, V$, and $Q$. 


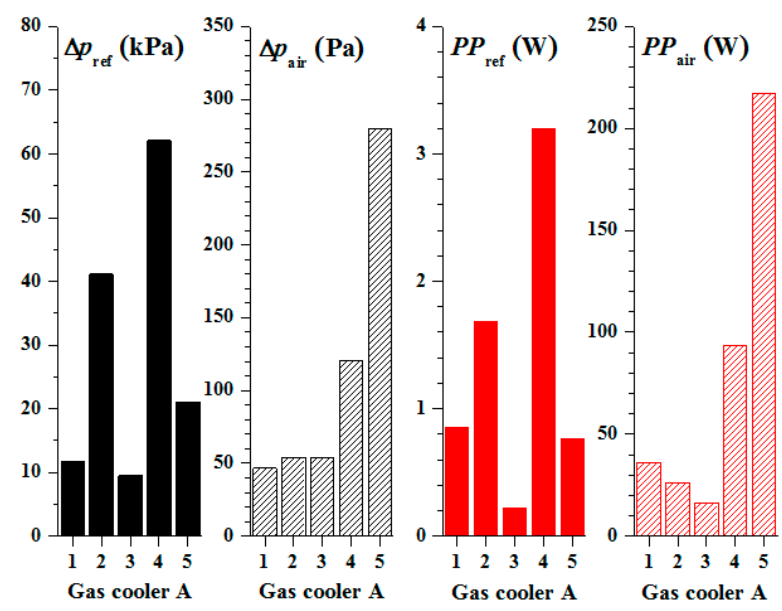

Figure 15. Comparison between $8 \mathrm{~mm}$ and $5 \mathrm{~mm}$ coils gas cooler A for $\Delta p_{\text {ref, }} \Delta p_{\text {air }}, P P_{\text {ref }}$, and $P P_{\text {air }}$.

Figures 16 and 17 show the comparisons for gas cooler B. The heat-transfer rate of gas cooler B with $5 \mathrm{~mm}$ tubes drops to $53.1 \%$ (for $L=1.6 \mathrm{~m}$ ) and $35.7 \%$ (for $L=1.0 \mathrm{~m}$ ) of those with $8 \mathrm{~mm}$ tubes for the same air velocity condition $v_{\text {air, in }}=2.4 \mathrm{~m} / \mathrm{s}$, and to $62.5 \%$ and $52.5 \%$ for the same air mass flow rate condition $\dot{m}_{\mathrm{air}, \text { in }}=1.7662 \mathrm{~kg} / \mathrm{s}$. The associated pressure drop of $\mathrm{sCO}_{2}$ is, respectively, 2.93 times and $90.5 \%$ for $v_{\text {air, in }}=2.4 \mathrm{~m} / \mathrm{s}$ and 3.95 and 1.84 times for $\dot{m}_{\text {air, in }}=1.7662 \mathrm{~kg} / \mathrm{s}$. For $\dot{m}_{\text {air, in }}=1.7662 \mathrm{~kg} / \mathrm{s}$, the pressure drop of air increases to 78.6 (for $L=1.6 \mathrm{~m}$ ) and $178.6 \mathrm{~Pa}$ (for $L=1.0 \mathrm{~m}$ ), which are much higher than the $31.4 \mathrm{~Pa}$ of the $8 \mathrm{~mm}$ tubes, resulting in the associated pumping power of air up to 123.1 and $279.9 \mathrm{~W}$. The higher pressure drop of $\mathrm{sCO}_{2}$ and larger consumption of air pumping power in the gas cooler with $5 \mathrm{~mm}$ coils will impact the overall efficiency of the $\mathrm{CO}_{2}$ refrigeration system.

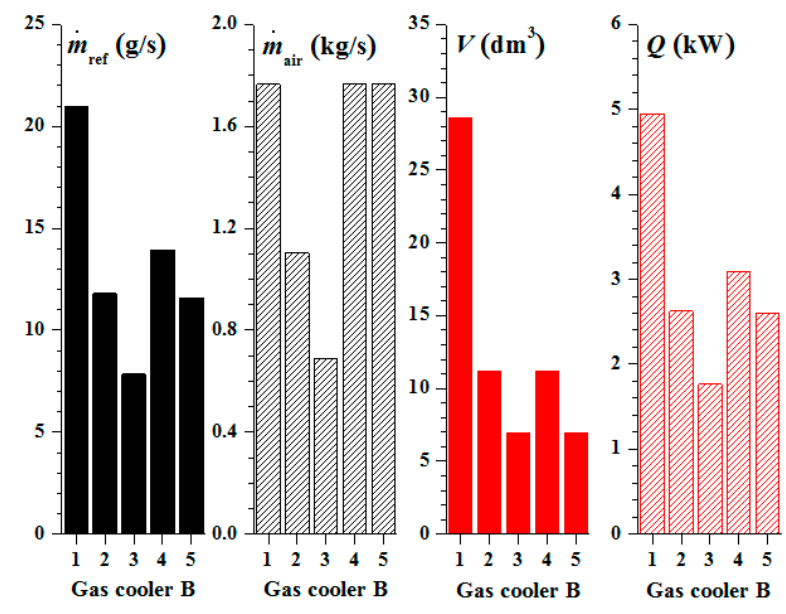

Figure 16. Comparison between $8 \mathrm{~mm}$ and $5 \mathrm{~mm}$ coils gas cooler B for $\dot{m}_{\mathrm{ref}}, \dot{m}_{\mathrm{air}}, V$, and $Q$. 


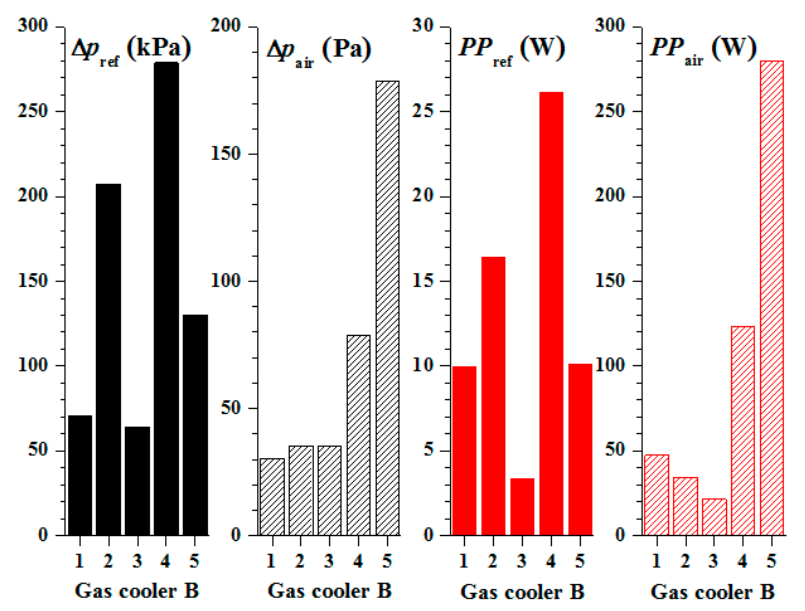

Figure 17. Comparison between $8 \mathrm{~mm}$ and $5 \mathrm{~mm}$ coils gas cooler $\mathrm{A}$ for $\Delta p_{\text {ref }}, \Delta p_{\text {air }}, P P_{\text {ref, }}$, and $P P_{\text {air }}$.

\section{Conclusions}

To investigate the thermohydraulic performance of finned-tube $\mathrm{sCO}_{2}$ gas coolers, a detailed mathematical model employing the distributed modelling approach and the $\varepsilon-N T U$ method was developed and presented in this study. The model was validated against experimental data and then employed to investigate the influence of design and operating parameters on the overall gas cooler performance. The following conclusions can be drawn from the results:

The refrigerant heat-transfer coefficient increases with decreasing temperature and reaches its maximum close to the pseudocritical temperature, before starting to decrease rapidly with further reductions in temperature. The air-side heat-transfer coefficient is one or two orders of magnitude lower than the refrigerant heat-transfer coefficient and reduces as the air flows through the heat exchanger in a cross flow direction to that of the refrigerant flow. It can also be observed that approximately $90 \%$ of the overall temperature drop of the $\mathrm{sCO}_{2}$ takes place at the first few pipes of the heat exchanger due to the large temperature difference between the $\mathrm{sCO}_{2}$ and air.

Increasing the refrigerant mass flow rate and reducing the tube diameter of the gas cooler can reduce significantly the footprint of the gas cooler but with a penalty of increased pressure drop. Higher pressure drop will cause an increase in the compressor power consumption and so the design optimization of gas coolers requires consideration not only of the effectiveness of the gas cooler itself but also the impact on overall system efficiency.

Reduction of the gas cooler size by reducing tube diameter can be achieved through optimization of the tube circuitry to reduce tube length. The modelling methodology presented in this paper can enable such optimizations for the benefit of other researchers in the field and gas cooler manufacturers.

Author Contributions: L.C. performed most of the conceptualization and methodology and prepared the original draft of the work. K.M.T. implemented experimental measurements and model validation. S.A.T. reviewed and provided comments on the different versions of the paper and obtained the funding that supported the work. All authors have read and agreed to the published version of the manuscript.

Funding: This research received funding from the UK Engineering and Physical Sciences Research Council (EPSRC), under grant numbers EP/P004636/1 and EP/K011820/1, and the European Union's Horizon 2020 research and innovation program grant number No. 680599.

Acknowledgments: The authors would like to acknowledge the financial support received by the project funders and the industry partners. All data used are included in the paper, but if any additional information is required it can be obtained by contacting the corresponding author.

Conflicts of Interest: The authors declare no conflict of interest. 


\section{Nomenclature}

\begin{tabular}{|c|c|}
\hline$A$ & area, $\mathrm{m}^{2}$ \\
\hline$c_{p}$ & specific heat, J/(kgK) \\
\hline C & heat capacity rate, $\mathrm{W} / \mathrm{K}$ \\
\hline$D$ & hydraulic diameter, $\mathrm{m}$; diameter, $\mathrm{m}$ \\
\hline$f$ & friction factor \\
\hline$F_{s}$ & fin spacing, $\mathrm{m}$ \\
\hline G & mass flux, $\mathrm{kg} /\left(\mathrm{m}^{2} \mathrm{~s}\right)$ \\
\hline$h$ & $\begin{array}{l}\text { heat-transfer coefficient, } \mathrm{W} /\left(\mathrm{m}^{2} \mathrm{~K}\right) \text {; specific enthalpy, } \\
\mathrm{J} \cdot \mathrm{kg}^{-1}\end{array}$ \\
\hline$i$ & segment number \\
\hline j & tube number \\
\hline$k$ & thermal conductivity, $\mathrm{W} /(\mathrm{mK})$; row number \\
\hline$L$ & length, $\mathrm{m}$ \\
\hline$m$ & exponent parameter \\
\hline$\dot{m}$ & mass flow rate, $\mathrm{kg} / \mathrm{s}$ \\
\hline$N$ & total segment number \\
\hline NTU & number of transfer units \\
\hline$N u$ & Nusselt number \\
\hline$p$ & pressure, $\mathrm{Pa}$ \\
\hline$P$ & tube pitch \\
\hline $\operatorname{Pr}$ & Prandtl number \\
\hline$Q$ & heat-transfer rate, $\mathrm{W}$ \\
\hline$r$ & radius, $\mathrm{m}$ \\
\hline$R$ & thermal resistance, $\mathrm{K} / \mathrm{W}$ \\
\hline $\operatorname{Re}$ & Reynolds number \\
\hline$R e_{\mathrm{Dc}}$ & Reynolds number based on tube collar diameter \\
\hline$S_{\mathrm{h}}$ & height of slit, $\mathrm{m}$ \\
\hline$S_{\mathrm{n}}$ & spacing in normal direction, $\mathrm{m}$; number of slit \\
\hline$S_{\mathrm{p}}$ & spacing in parallel direction, $\mathrm{m}$ \\
\hline$S_{\mathrm{s}}$ & breadth of a slit in airflow direction, $\mathrm{m}$ \\
\hline$T$ & temperature, $\mathrm{K}$ \\
\hline$U$ & overall heat-transfer coefficient, $\mathrm{W} /\left(\mathrm{m}^{2} \mathrm{~K}\right)$ \\
\hline$\Delta p$ & pressure drop, $\mathrm{Pa}$ \\
\hline$x$ & refrigerant flow direction \\
\hline$X_{\mathrm{L}}$ & parameter \\
\hline$X_{\mathrm{M}}$ & parameter \\
\hline Greek letters & \\
\hline$\rho$ & density, $\mathrm{kg} / \mathrm{m}^{3}$ \\
\hline$\mu$ & dynamic viscosity, Pa.s \\
\hline$\varepsilon$ & effectiveness \\
\hline$\eta$ & efficiency \\
\hline$\delta$ & thickness, $\mathrm{m}$ \\
\hline Subscripts & \\
\hline $\mathrm{a}$ & air \\
\hline cal & calculation \\
\hline eq & equivalent \\
\hline$f$ & fin \\
\hline$i$ & segment number \\
\hline in & inlet \\
\hline$l$ & longitudinal \\
\hline
\end{tabular}




$\begin{array}{ll}\max & \text { maximum } \\ \min & \text { minimum } \\ \bmod & \text { modelling } \\ \mathrm{n} & \text { normal } \\ \mathrm{p} & \text { parallel } \\ \text { ref } & \text { refrigerant } \\ \mathrm{t} & \text { transverse } \\ \text { out } & \text { outlet } \\ \mathrm{w} & \text { wall }\end{array}$

\section{References}

1. Lorentzen, G. Trans-Critical Vapour Compression Cycle Device. International Patent Publication WO90/07683, 12 July 1990.

2. Austin, B.T.; Sumathy, K. Transcritical carbon dioxide heat pump systems: A review. Renew. Sustain. Energy Rev. 2011, 15, 4013-4029. [CrossRef]

3. Nekså, P. $\mathrm{CO}_{2}$ heat pump systems. Int. J. Refrig. 2002, 25, 421-427. [CrossRef]

4. Kim, M.H.; Pettersen, J.; Bullard, C.W. Fundamental process and system design issues in $\mathrm{CO}_{2}$ vapor compression systems. Prog. Energy Combust. Sci. 2004, 30, 119-174. [CrossRef]

5. Cavallini, A.; Cecchinato, L.; Corradi, M.; Fornasieri, E.; Zilio, C. Two-stage transcritical carbon dioxide cycle optimisation: A theoretical and experimental analysis. Int. J. Refrig. 2005, 28, 1274-1283. [CrossRef]

6. Pettersen, J.; Hafner, A.; Skaugen, G.; Rekstad, H. Development of compact heat exchangers for $\mathrm{CO}_{2}$ air-conditioning systems. Int. J. Refrig. 1998, 21, 180-193. [CrossRef]

7. Hwang, Y.; Jin, D.H.; Radermacher, R.; Hutchins, J.W. Performance measurement of $\mathrm{CO}_{2}$ heat exchangers. ASHRAE Trans. 2005, 111, 306-316.

8. Zilio, C.; Cecchinato, L.; Corradi, M.; Schiochet, G. An assessment of heat transfer through fins in a fin-and-tube gas cooler for transcritical carbon dioxide cycles. HVAC R Res. 2007, 13, 457-469. [CrossRef]

9. Ge, Y.T.; Tassou, S.A.; Santosa, I.D.; Tsamos, K. Design optimisation of $\mathrm{CO}_{2}$ gas cooler/condenser in a refrigeration system. Appl. Energy 2015, 160, 973-981. [CrossRef]

10. Tsamos, K.M.; Ge, Y.T.; Santosa, I.; Tassou, S.A. Experimental investigation of gas cooler/condenser designs and effects on a $\mathrm{CO}_{2}$ booster system. Appl. Energy 2017, 186, 470-479. [CrossRef]

11. Santosa, I.D.M.C.; Gowreesunker, B.L.; Tassou, S.A.; Tsamos, K.M.; Ge, Y. Investigations into air and refrigerant side heat transfer coefficients of finned-tube $\mathrm{CO}_{2}$ gas coolers. Int. J. Heat Mass Transf. 2017, 107, 168-180. [CrossRef]

12. Ge, Y.T.; Cropper, R.T. Simulation and performance evaluation of finned-tube $\mathrm{CO}_{2}$ gas coolers for refrigeration systems. Appl. Therm. Eng. 2009, 29, 957-965. [CrossRef]

13. Singh, V.; Aute, V.; Radermacher, R. Investigation of effect of cut fins on carbon dioxide gas cooler performance. HVAC R Res. 2010, 16, 513-527. [CrossRef]

14. Gupta, D.K.; Dasgupta, M.S. Simulation and performance optimization of finned tube gas cooler for trans-critical $\mathrm{CO}_{2}$ refrigeration system in Indian context. Int. J. Refrig. 2014, 38, 153-167. [CrossRef]

15. Marcinichen, J.B.; Thome, J.R.; Pereira, R.H. Working fluid charge reduction. Part II: Supercritical $\mathrm{CO}_{2}$ gas cooler designed for light commercial appliances. Int. J. Refrig. 2016, 65, 273-286. [CrossRef]

16. London, A.L.; Seban, R.A. A generalization of the methods of heat exchanger analysis. Int. J. Heat Mass Transf. 1980, 23, 5-16. [CrossRef]

17. Krasnoshchekov, E.A.; Kuraeva, I.V.; Protopopov, V.S. Local heat transfer of carbon dioxide at supercritical pressure under cooling conditions. Teplofiz. Vysok. Temp. 1969, 7, 922-930.

18. Fang, $\mathrm{X} . ; \mathrm{Xu}, \mathrm{Y}$. Modified heat transfer equation for in-tube supercritical $\mathrm{CO}_{2}$ cooling. Appl. Therm. Eng. 2011, 31, 3036-3042. [CrossRef]

19. Jackson, J.D.; Hall, W.B. Influences of buoyancy on heat transfer to fluids flowing in vertical tubes under turbulent conditions. In Turbulent Forced Convection in Channels and Bundles, 1st ed.; Hemisphere: New York, NY, USA, 1979; Volume 2, pp. 613-640.

20. Bourke, P.J.; Pulling, D.J.; Gill, L.E.; Denton, W.H. Forced convective heat transfer to turbulent $\mathrm{CO}_{2}$ in the supercritical region. Int. J. Heat Mass Transf. 1970, 13, 1339-1348. [CrossRef] 
21. Liao, S.M.; Zhao, T.S. An experimental investigation of convection heat transfer to supercritical carbon dioxide in miniature tubes. Int. J. Heat Mass Transf. 2002, 45, 5025-5034. [CrossRef]

22. Pidaparti, S.R.; McFarland, J.A.; Mikhaeil, M.M.; Anderson, M.H.; Ranjan, D. Investigation of buoyancy effects on heat transfer characteristics of supercritical carbon dioxide in heating mode. J. Nucl. Eng. Radiat. Sci. 2015, 1, 031001. [CrossRef]

23. Jiang, P.X.; Xu, Y.J.; Lv, J.; Shi, R.-F.; He, S.; Jackson, J.D. Experimental investigation of convection heat transfer of $\mathrm{CO}_{2}$ at super-critical pressures in vertical mini-tubes and in porous media. Appl. Therm. Eng. 2004, 24, 1255-1270. [CrossRef]

24. Jiang, P.X.; Shi, R.F.; Xu, Y.J.; He, S.; Jackson, J.D. Experimental investigation of flow resistance and convection heat transfer of $\mathrm{CO}_{2}$ at supercritical pressures in a vertical porous tube. J. Supercrit. Fluids 2006, 38, 339-346. [CrossRef]

25. Jiang, P.X.; Shi, R.F.; Zhao, C.R.; Xu, Y.J. Experimental and numerical study of convection heat transfer of $\mathrm{CO}_{2}$ at supercritical pressures in vertical porous tubes. Int. J. Heat Mass Transf. 2008, 51, 6283-6293. [CrossRef]

26. Wang, C.C.; Lee, W.S.; Sheu, W.J. A comparative study of compact enhanced fin-and-tube heat exchangers. Int. J. Heat Mass Transf. 2001, 44, 3565-3573. [CrossRef]

27. Schmidt, T.E. Heat transfer calculations for extended surfaces. Refrig. Eng. 1949, 57, 351-357.

28. Liao, S.M.; Zhao, T.S. Measurements of heat transfer coefficients from supercritical carbon dioxide flowing in horizontal mini/micro channels. Trans. Am. Soc. Mech. Eng. J. Heat Transf. 2002, 124, 413-420. [CrossRef]

29. Dang, C.; Iino, K.; Fukuoka, K.; Hihara, E. Effect of lubricating oil on cooling heat transfer of supercritical carbon dioxide. Int. J. Refrig. 2007, 30, 724-731. [CrossRef]

30. Cheng, L.; Ribatski, G.; Thome, J.R. Analysis of supercritical $\mathrm{CO}_{2}$ cooling in macro-and micro-channels. Int. J. Refrig. 2008, 31, 1301-1316. [CrossRef]

31. Oh, H.K.; Son, C.H. New correlation to predict the heat transfer coefficient in-tube cooling of supercritical $\mathrm{CO}_{2}$ in horizontal macro-tubes. Exp. Therm. Fluid Sci. 2010, 34, 1230-1241. [CrossRef]

(C) 2020 by the authors. Licensee MDPI, Basel, Switzerland. This article is an open access article distributed under the terms and conditions of the Creative Commons Attribution (CC BY) license (http://creativecommons.org/licenses/by/4.0/). 